\title{
Lactose in milk replacer can partly be replaced by glucose, fructose, or glycerol without affecting insulin sensitivity in veal calves
}

\author{
A. J. Pantophlet, ${ }^{* 1}$ M. S. Gilbert, † J. J. G. C. van den Borne,† W. J. J. Gerrits,† H. Roelofsen, $\ddagger$ M. G. Priebe, ${ }^{*}$ \\ and R. J. Vonkł \\ *Department of Pediatrics, Center for Liver, Digestive and Metabolic Diseases, University Medical Centre Groningen, PO Box 30001 , \\ 9700 RB Groningen, the Netherlands \\ †Animal Nutrition Group, Wageningen University, PO Box 338, 6700 AH Wageningen, the Netherlands \\ ¥Medical Biomics, University Medical Centre Groningen, PO Box 30001, 9700 RB Groningen, the Netherlands
}

\begin{abstract}
Calf milk replacer (MR) contains 40 to $50 \%$ lactose. Lactose strongly fluctuates in price and alternatives are desired. Also, problems with glucose homeostasis and insulin sensitivity (i.e., high incidence of hyperglycemia and hyperinsulinemia) have been described for heavy veal calves (body weight $>100 \mathrm{~kg}$ ). Replacement of lactose by other dietary substrates can be economically attractive, and may also positively (or negatively) affect the risk of developing problems with glucose metabolism. An experiment was designed to study the effects of replacing one third of the dietary lactose by glucose, fructose, or glycerol on glucose homeostasis and insulin sensitivity in veal calves. Forty male Holstein-Friesian (body weight $=114 \pm 2.4 \mathrm{~kg}$; age $=97 \pm 1.4 \mathrm{~d}$ ) calves were fed an MR containing $462 \mathrm{~g}$ of lactose $/ \mathrm{kg}(\mathrm{CON})$, or an MR in which $150 \mathrm{~g}$ of lactose $/ \mathrm{kg}$ of $\mathrm{MR}$ was replaced by glucose (GLU), fructose (FRU), or glycerol (GLY). During the first $10 \mathrm{~d}$ of the trial, all calves received CON. The CON group remained on this diet and the other groups received their experimental diets for a period of $8 \mathrm{wk}$. Measurements were conducted during the first (baseline) and last week of the trial. A frequently sampled intravenous glucose tolerance test was performed to assess insulin sensitivity and $24 \mathrm{~h}$ of urine was collected to measure glucose excretion. During the last week of the trial, a bolus of $1.5 \mathrm{~g}$ of $\left[\mathrm{U}_{-}{ }^{13} \mathrm{C}\right]$ substrates was added to their respective meals and plasma glucose, insulin, and ${ }^{13} \mathrm{C}$-glucose responses were measured. Insulin sensitivity was low at the start of the trial and remained low $[1.2 \pm 0.1$ and $1.0 \pm$ $\left.0.1(\mathrm{mU} / \mathrm{L})^{-1} \times \mathrm{min}^{-1}\right]$, and no treatment effect was noted. Glucose excretion was low at the start of the trial $(3.4 \pm 1.0 \mathrm{~g} / \mathrm{d})$, but increased in CON and GLU calves $(26.9 \pm 3.9$ and $43.0 \pm 10.6 \mathrm{~g} / \mathrm{d})$ but not in FRU and GLY calves. Postprandial glucose was higher in
\end{abstract}

Received August 18, 2015.

Accepted December 5, 2015.

${ }^{1}$ Corresponding author: a.j.pantophlet@umcg.nl
GLU, lower in FRU, and similar in GLY compared with CON calves. Postprandial insulin was lower in FRU and GLY and similar in GLU compared with CON calves. Postprandial ${ }^{13} \mathrm{C}$-glucose increased substantially in FRU and GLY calves, indicating that calves are able to partially convert these substrates to glucose. We concluded that replacing one third of lactose in MR by glucose, fructose, or glycerol in MR differentially influences postprandial glucose homeostasis but does not affect insulin sensitivity in veal calves.

Key words: veal calves, fructose, glycerol, insulin sensitivity, glucose homeostasis

\section{INTRODUCTION}

Veal calves are fed milk replacer (MR), roughage, and concentrates. Despite the tendency to increase the amounts of roughage and concentrates in the diet, the vast majority (60-70\%) of the digestible nutrient intake originates from MR. Upon closure of the esophageal groove, MR bypasses the rumen and flows directly into the abomasum. Lactose is the predominant, if not the only, carbohydrate source in MR. Calf MR commonly contains approximately $45 \%$ lactose, which is efficiently digested and absorbed from the calf intestinal lumen (Burt and Irvine, 1970; Coombe and Smith, 1974).

However, the commercial availability of lactose (or whey) for feed applications is limited and not constant, resulting in large fluctuations in raw material prices. This provides an economic incentive for MR manufacturers to replace lactose by alternative energy sources.

Importantly, a prolonged high intake of lactose, combined with substantial amounts of fat, has been associated with impaired glucose homeostasis. Hyperglycemia, hyperinsulinemia, and insulin resistance have been observed in veal calves in the second phase of the fattening period (Hostettler-Allen et al., 1994; Hugi et al., 1997). Such metabolic problems may eventually result in diabetes and (pro)inflammatory stress, as demonstrated in humans (Hotamisligil, 2006; Shoelson et al., 2006), and in hepatic steatosis (Gerrits et al., 2008). 
Starch or starch-based products, such as maltodextrins, are the most obvious alternatives for lactose. These products are widely available and are also attractive from an economic perspective. However, we recently demonstrated (Gilbert et al., 2015a) that calves have difficulties digesting starch-based products from MR diets, probably due to low activities of $\alpha$-amylase and maltase in the small intestine. Nonetheless, the vast majority of starch does not reach the end of the small intestine, which can probably be explained by fermentation (Gilbert et al., 2015a,b).

Apart from starch-based products, glucose, fructose, and glycerol may also replace lactose in MR. Partly replacing lactose by fructose and glycerol may beneficially affect postprandial glucose homeostasis. These substrates have lower glycemic (and insulinemic) responses than lactose (Foster-Powell et al., 2002). It is believed that a lower glycemic (and insulinemic) response is beneficial for health, especially in subjects with impaired glucose metabolism (Howlett and Ashwell, 2008). In humans, fructose and glycerol are almost completely absorbed and metabolized by the liver (Grunnet and Lundquist, 1967; Schaefer et al., 2009; Sun and Empie, 2012). Therefore, the effects of these substrates on postprandial glucose homeostasis will likely depend on the rate and extent of conversion of these substrates to glucose by the liver. In humans, fructose is only partly $(29-51 \%)$ converted to glucose by the liver (Sun and Empie, 2012); whether this is also the case for veal calves is not clear. Compared with fructose and glycerol, glucose may lead to higher glycemic (and insulinemic) responses than lactose (Foster-Powell et al., 2002), and thus may negatively affect postprandial glucose homeostasis. Whether prolonged exposure to these substrates (as partial replacer of lactose in veal calves) also affects insulin sensitivity is not known.

The objective of the current study was, therefore, to study the effects of partial replacement of dietary lactose by glucose, fructose, and glycerol on glucose homeostasis and insulin sensitivity (IS) in veal calves. The effects on energy and protein utilization for growth were also assessed and described elsewhere (Gilbert et al., 2016)

\section{MATERIALS AND METHODS}

\section{Animals and Housing}

Forty male Holstein-Friesian calves were housed at the research facility of the Department of Animal Sciences at Wageningen University. At start of the trial calves were $97 \pm 1.4 \mathrm{~d}$ of age and weighted $114 \pm 2.4$ $\mathrm{kg}$ (means \pm SEM).

Calves were housed in groups, except for the last 6 $\mathrm{d}$ of the pre-experimental period (i.e., first $10 \mathrm{~d}$ of the trial) and the last $14 \mathrm{~d}$ of the trial. During these periods calves were housed individually in metabolic cages $($ dimensions $=0.80 \times 1.8 \mathrm{~m})$. During group housing, calves were housed in pens ( 5 calves/pen), which were fitted with wooden slatted floors and galvanized fencing. Per calf, $2 \mathrm{~m}^{2}$ was available. Ventilation occurred by ceiling fans, and illumination by natural light and artificial (fluorescent lamps) light between 0630 and $1730 \mathrm{~h}$. The average temperature and humidity were $18.5 \pm 0.4^{\circ} \mathrm{C}$ and $69.5 \pm 1.2 \%$, respectively (means \pm SEM). The experimental procedures were approved by the Animal Care and Use Committee of Wageningen University.

\section{Experimental Design, Diets, and Feeding}

Calves were fed 2.0 times the ME requirements for maintenance, which was set at $460 \mathrm{~kJ} / \mathrm{kg}$ of metabolic BW per day (Van Es et al., 1967). Individual BW were measured weekly and the feeding rate was adjusted accordingly.

The trial consisted of a pre-experimental period (first $10 \mathrm{~d}$ ) and an experimental period of $55 \mathrm{~d}$. During the pre-experimental period, all calves received the control MR diet, which contained $462 \mathrm{~g}$ of lactose $/ \mathrm{kg}$ of $\mathrm{MR}$. The composition of the MR is given in Table 1 . Thereafter, calves were assigned to 1 of 4 dietary treatments. The control group (CON) remained on the control MR diet; in the other groups $150 \mathrm{~g}$ of lactose (per $\mathrm{kg}$ of MR) was replaced by isoenergetic amounts of either glucose (GLU; Tereos Syral, Marckolsheim, France), fructose (FRU; Tate \& Lyle Europe, Boleraz, Slovakia) or glycerol (GLY; Triconor Distribution BV, Soest, the Netherlands). All calves remained on their respective diets for a period of $55 \mathrm{~d}$. The introduction of the lactose replacers occurred gradually, by increasing the lactose replacement by $50 \mathrm{~g} / \mathrm{kg}$ of MR every $3 \mathrm{~d}$.

In addition to MR, each calf received $10 \mathrm{~g}$ of $\mathrm{DM}$ of solid feed per kilogram of metabolic BW per day. The solid feed consisted of $80 \%$ concentrates and $20 \%$ wheat straw (based on DM). The concentrates were composed of $279 \mathrm{~g} / \mathrm{kg}$ of barley, $458 \mathrm{~g} / \mathrm{kg}$ of corn, $205 \mathrm{~g} / \mathrm{kg}$ of lupines, $24 \mathrm{~g} / \mathrm{kg}$ of palm oil, and $34 \mathrm{~g} / \mathrm{kg}$ of premix.

Milk replacer was fed on individual basis, at a concentration of $140 \mathrm{~g}$ of $\mathrm{MR} / \mathrm{L}$ and supplied at a temperature of $\sim 42^{\circ} \mathrm{C}$. The concentration increased to $160 \mathrm{~g} / \mathrm{L}$ of water when the MR volume $\geq 9.0 \mathrm{~L}$. Solid feed was provided per pen ( 5 calves/pen) during group housing, and per individual calf when the calves were housed in metabolic cages. Calves were allowed ad libitum access to water. Feeding took place twice a day, at 0630 and 1530 h, via buckets. Milk replacer was supplied first, followed by solid feed. Milk replacer refusals (max 60 min after feeding) were weighed and recorded twice a 
Table 1. Composition of the control (CON) milk replacer

\begin{tabular}{lc}
\hline Item & Measurement \\
\hline Basal milk replacer $(\mathrm{g} / \mathrm{kg})$ & \\
Delactosed whey powder & 244.5 \\
Calcium formate & 7.5 \\
Coconut oil & 39.2 \\
Lard & 72.5 \\
Tallow & 72.5 \\
Lecithin & 5.9 \\
Ricinoleate emulsion & 5.9 \\
Premix ${ }^{1}$ & 10 \\
Whey protein concentrate & 391.1 \\
Methionine & 1.1 \\
Additional (g/kg) & 150 \\
Lactose & \\
Nutrients (g/kg of DM, unless noted) & 966 \\
DM ${ }^{3}$ (g/kg) & 205 \\
CP & 209 \\
Crude fat & 74 \\
Crude ash & 478 \\
Lactose & 49.9 \\
Fe (mg/kg of DM) & 19.8 \\
Gross energy (MJ/kg) & \\
\hline
\end{tabular}

${ }^{1}$ Premix (per kg): CP, 0.7 g; starch, 5.0 g; crude ash, 1.5 g; Ca, $17 \mathrm{mg}$; P, $7.5 \mathrm{mg}$; Na, $0.7 \mathrm{mg}$; K, $7.3 \mathrm{mg}$; Cl, $13 \mathrm{mg} ; \mathrm{Mg}, 0.5 \mathrm{~g} ; \mathrm{Fe}, 45 \mathrm{mg}$; $\mathrm{Cu}, 8.0 \mathrm{mg}$; Zn, $0.1 \mathrm{~g}$; Mn, $43 \mathrm{mg}$; Se, $0.3 \mathrm{mg}$; I, $1.0 \mathrm{mg}$; vitamin A $25,013 \mathrm{IU}$; vitamin $\mathrm{D}_{3}, 4,002 \mathrm{IU}$; vitamin $\mathrm{E}, 150 \mathrm{IU}$; vitamin $\mathrm{K}_{3}, 2.1$ $\mathrm{mg}$; vitamin $\mathrm{C}, 0.3 \mathrm{~g}$; vitamin $\mathrm{B}_{1}, 8.2 \mathrm{mg}$; vitamin $\mathrm{B}_{2}, 10 \mathrm{mg}$; vitamin $\mathrm{B}_{3}, 35 \mathrm{mg}$; vitamin $\mathrm{B}_{5}, 18 \mathrm{mg}$; vitamin $\mathrm{B}_{6}, 10 \mathrm{mg}$; vitamin $\mathrm{B}_{12}, 0.1 \mathrm{mg}$; biotin, $0.2 \mathrm{mg}$; folate, $0.7 \mathrm{mg}$; choline, $0.4 \mathrm{~g}$.

${ }^{2}$ For the glucose, fructose, and glycerol groups, $150 \mathrm{~g}$ of lactose $/ \mathrm{kg}$ of meal replacer was replaced isoenergetically by glucose, fructose, and glycerol, respectively.

${ }^{3}$ Dry matter of the basal milk replacer.

${ }^{4}$ Calculated content.

day before solid feed supply, whereas solid feed refusals were weighed and recorded once a day before the morning MR feeding.

\section{Experimental Procedures}

The measurements were concentrated during the preexperimental period (first $10 \mathrm{~d}$ of trial; measurement period 1) and last $7 \mathrm{~d}$ of the trial (measurement period 2).

Frequently Sampled Intravenous Glucose Tolerance Test. A frequently sampled intravenous glucose tolerance test (FSIGTT) was performed during both measurement periods (on d 9 and 65 of the trial). Five (measurement period 1) and $12 \mathrm{~d}$ (measurement period 2) before the test, calves were moved to metabolic cages and were prepared with a central venous catheter (Careflow, Becton Dickinson, Alphen a/d Rijn, the Netherlands) in their jugular vein, for glucose and insulin infusion, and blood sampling.

All calves were fasted overnight for 16 to $19 \mathrm{~h}$ before the FSIGTT. At 0 min, an intravenous glucose bolus of $0.3 \mathrm{~g} / \mathrm{kg}$ of BW (20\% glucose solution, B. Braun,
Oss, the Netherlands) was administered within 2 min, followed by an intravenous insulin bolus of $0.03 \mathrm{IU} /$ $\mathrm{kg}$ of BW (100 IU/mL of solution, Insuman Rapid, Sanofi-Aventis, Gouda, the Netherlands) at $20 \mathrm{~min}$ (administered within $1 \mathrm{~min}$ ). Blood samples were collected from the jugular catheter at $-8,-4,2,4,6,8$, $10,12,14,16,19,22,25,30,35,40,50,60,75,90,120$, 150 , and $180 \mathrm{~min}$ relative to the intravenous glucose bolus. Blood samples were transferred immediately into 6-mL lithium-heparin vacutainer tubes (Becton Dickinson, Breda, the Netherlands) and stored on ice. Plasma was collected, after centrifugation $(1,516 \times g$, $10 \mathrm{~min}$ ), within $1.5 \mathrm{~h}$ after blood sampling and stored at $-20^{\circ} \mathrm{C}$ until analysis of plasma glucose and insulin concentrations. In addition, plasma triglycerides and high-density and low-density lipoprotein (HDL and LDL, respectively) cholesterol concentrations were analyzed in the fasting plasma samples.

The IS index was calculated according to Bergman's minimal model approach, using MinMod Millennium (MinMod Inc., Los Angeles, CA; version 6.0.2), a computer-based software for the calculation of IS from FSIGTT data (Pacini and Bergman, 1986; Boston et al., 2003). Insulin sensitivity derived by this method (IS $\mathbf{S}_{\text {minmod }}$ ) encompasses both peripheral and hepatic IS (Bergman et al., 1979). Therefore, another index of insulin sensitivity, the quantitative insulin sensitivity index (QUICKI), was calculated from the fasting plasma glucose and insulin levels collected during the FSIGTT. The QUICKI primary reflects hepatic IS (Chen et al., 2003; Muniyappa et al., 2008). This index was calculated using the following formula:

$$
\text { QUICKI }=\frac{1}{[\log (\text { glucose }, \mathrm{mg} / \mathrm{dL})+\log (\text { insulin, } \mathrm{mU} / \mathrm{L})]} \text {. }
$$

Urine Collection. Prior to catheterization (for the FSIGTT), calves were shaved (especially the tail region) and harnessed. Plastic bags were connected to the harness to collect feces. Clean urine was quantitatively collected for a period of 3 and $5 \mathrm{~d}$, during measurement period 1 and 2, respectively. The urine was collected via funnels in buckets, which were placed under the cages. Each bucket contained 1,500 $\mathrm{mL}$ of a $25 \%$ sulfuric acid solution (BOOM, Meppel, the Netherlands). At the end of the collection period, the amount of urine was weighed and an aliquot of $100 \mathrm{~mL}$ was transferred into a urine collection cup and frozen at $-20^{\circ} \mathrm{C}$ until analysis of glucose, catecholamines, and cortisol.

Postprandial Blood Glucose, ${ }^{13} \mathrm{C}$-Glucose, and Insulin Concentrations. On d 61 of the trial (measurement period 2), a bolus of $1.5 \mathrm{~g}$ of $\left[\mathrm{U}_{-}{ }^{13} \mathrm{C}\right]$ enriched substrates (99\% isotopic enrichment; Cambridge Iso- 
tope Laboratories, Tewksbury, MA) was added to the morning MR meal. Hence, GLU calves received $\left[\mathrm{U}_{-}{ }^{13} \mathrm{C}\right]$ glucose, FRU calves received $\left[\mathrm{U}_{-}{ }^{13} \mathrm{C}\right]$ fructose, and GLY calves received $\left[\mathrm{U}_{-}{ }^{13} \mathrm{C}\right]$ glycerol, whereas $\mathrm{CON}$ calves did not receive ${ }^{13} \mathrm{C}$-enriched substrates. Solid feed was not provided during this (enriched) test meal.

Blood samples were collected from the jugular vein at $-10,15,30,60,120,180,240,300$, and 360 min relative to MR feeding. Blood samples were transferred into 6-mL lithium heparin Vacutainer tubes (Becton Dickinson) and stored on ice. Plasma was collected, after centrifugation $(1,516 \times g, 10 \mathrm{~min})$, within $1.5 \mathrm{~h}$ after blood sampling and was stored at $-20^{\circ} \mathrm{C}$ until analysis. Plasma glucose and insulin concentrations as well as ${ }^{13} \mathrm{C}$ enrichment in plasma glucose were measured. For glucose and insulin, the maximum concentration minus fasting concentration $\left(\Delta \mathbf{C}_{\max }\right)$, time to maximum concentration, and the incremental area under the curve $\left(\mathbf{i A U C}_{0-6 \mathrm{~h}}\right.$ ) were calculated. For ${ }^{13} \mathrm{C}$ enrichment in plasma glucose, only the $\mathrm{iAUC}_{0-6 \mathrm{~h}}$ was calculated. The iAUC $_{066 \mathrm{~h}}$ was calculated using the trapezoid method (Le Floch et al., 1990).

\section{Laboratory Analyses}

Plasma glucose, triglycerides, and HDL and LDL cholesterol were measured on a Roche-Hitachi Modular automatic analyzer (Roche Diagnostics, Basel, Switzerland) using enzymatic colorimetric methods. The within- and between-run coefficient of variation were $\leq 2 \%$ for all analysis. Insulin was measured using a bovine ELISA kit (Mercodia, Uppsala, Sweden). The within- and between-run coefficient of variation were $\leq 5.6$ and $8.2 \%$, respectively.

Catecholamines in urine were measured using an online solid phase extraction-liquid chromatography/tandem mass spectrometry method previously described by de Jong et al. (2010). Cortisol was measured using the online solid phase extraction-liquid chromatography/tandem mass spectrometry method described by Jones et al. (2012). This method was originally devolved for saliva samples but was successfully applied on urine samples. The ${ }^{13} \mathrm{C}$-to- $-{ }^{12} \mathrm{C}$ ratio in plasma glucose was measured using a modified version of the gas chromatography-combustion-isotope ratio mass spectrometry method previously described by Vonk et al. (2000a, b). The modifications are described in detail elsewhere (Eelderink et al., 2012). A calibration curve was used to calculate the molar percentage excess (7 standards; range $=0.01-2.00$ molar percent excess) of the measured samples. Then, the molar percentage excess was multiplied by the plasma glucose concentration to obtain $\Delta\left[{ }^{13} \mathrm{C}\right]$-glucose concentrations.

\section{Statistical Analysis}

The SPSS (Version 22, IBM Corp., Armonk, NY) statistical software was used for all statistical analyses. Data are presented as means \pm SEM. The effects of treatment on insulin sensitivity, urinary glucose excretion, and fasting blood levels of glucose, insulin, cholesterol, triglycerides, catecholamines, and cortisol were tested by ANOVA using the GLM (Univariate) procedure. Treatment was used as factor and calf was the experimental unit. The final values (measurement period 2) were used as a dependent variable, with their respective initial values (pre-experimental; measurement period 1) as a covariate. Growth and data derived from postprandial blood concentrations (i.e., $\Delta \mathrm{C}_{\max }$, time to maximum, and $\mathrm{iAUC}_{0-6 \mathrm{~h}}$ ) were also tested for treatment effects using the same procedure. However, no covariates were included in the model.

Normality of the studentized residuals was assessed by visual inspection. Non-normally distributed data were $(\log )$ transformed to obtain normality. $P$-values $<0.05$ were considered significant and $P$-values $<0.10$ were considered a trend toward significance. When treatment effects were significant, the Šidák (1967) method was used to correct for pairwise comparisons.

\section{RESULTS}

No difference in feed refusals was noted between groups. However, 1 calf in the GLU group was excluded from the trial due to ruminal drinking. The ADG, measured over the 65 -d trial period, was, on average, $1.19 \pm$ $0.03 \mathrm{~kg} / \mathrm{d}$ and did not differ between treatments.

IS

Initial values for $\mathrm{IS}_{\text {minmod }}$ and QUICKI (measured during the pre-experimental period) were $1.2 \pm 0.1 \times$ $10^{-4}\left[(\mathrm{mU} / \mathrm{L})^{-1} \times \mathrm{min}^{-1}\right]$ and $0.371 \pm 0.001$, respectively. These values decreased by 18 and $10 \%$, respectively, on average, during the trial, but these changes were not affected by dietary treatment (Table 2).

\section{Fasting Blood Metabolites and Hormones}

Fasting plasma glucose concentrations (collected during the FSIGTT) were greater $(P<0.05)$ for FRU calves $(5.8 \mathrm{mmol} / \mathrm{L})$ than for GLU calves $(5.3 \mathrm{mmol} / \mathrm{L}$; Table 2). Fasting plasma insulin concentrations, however, were not affected by treatment but increased by $78 \%$ during the trial. Fasting triglyceride concentrations were not affected by treatment but decreased by 64\%. Fasting HDL and LDL cholesterol concentrations were not affected by treatment. 


\section{Postprandial Glucose, Insulin, and ${ }^{13} \mathrm{C}$ Enrichment in Plasma Glucose}

Postprandial blood glucose and insulin concentrations were measured after $51 \mathrm{~d}$ of adaptation to the experimental diets. On this day, fasting glucose and insulin concentrations were measured again for calculation of the postprandial parameters (Table 3 ). The treatment effects did not differ from the fasting measurements conducted during the FSIGTT (Table 2). Directly after feeding, plasma glucose, and insulin concentrations increased (Figure 1), but the time to the maximum plasma concentrations of glucose and insulin did not differ between treatments. The postprandial increase in plasma glucose concentration $\left(\Delta \mathrm{C}_{\max }\right)$ differed between treatments, with the levels being higher $(P<0.05)$ in GLU calves than in FRU and GLY calves. The $\Delta \mathrm{C}_{\max }$ for insulin also differed between treatments, with the levels being higher $(P<0.05)$ in GLU and CON calves than in FRU calves. The iAUC $_{0-6 \mathrm{~h}}$ for glucose was higher $(P<0.05)$ for GLU calves than the other calves, and higher $(P<0.05)$ for CON calves than for FRU calves. The iAUC ${ }_{0-6 \mathrm{~h}}$ for insulin was higher $(P<$ $0.05)$ for GLU and CON calves than for FRU and GLY calves. The iAUC ${ }_{0-6 \mathrm{~h}}$ for the $\Delta\left[{ }^{13} \mathrm{C}\right]$-glucose did differ between treatments, with GLU > GLY > FRU (Figure 2; Table 3).

\section{Urinary Glucose Excretion}

During the pre-experimental period, urinary glucose excretion was low $(3.4 \pm 1.0 \mathrm{~g} / \mathrm{d})$. At the end of the trial (i.e., after $55 \mathrm{~d}$ of adaptation to the experimental diets), the glucose excretion was significantly $(P<$ $0.01)$ higher for CON and GLU calves (26.9 \pm 3.9 and $43.0 \pm 10.6 \mathrm{~g} / \mathrm{d}$, respectively; Table 2), compared with the FRU and GLY calves.

\section{Urinary Excretion of Catecholamines and Cortisol}

The urinary excretion of 4 stress-related markers (adrenaline, noradrenaline, dopamine, and cortisol) was measured during this trial. Urinary excretion of these stress-related markers was not affected by dietary treatments (Table 2).

\section{DISCUSSION}

\section{Fructose and Glycerol Gluconeogenesis}

The total postprandial blood glucose response $\left(\mathrm{iAUC}_{0-6 \mathrm{~h}}\right.$ ) was higher for GLU calves than for the other calves, and higher for CON calves than for FRU calves. In general, blood glucose levels reflect both the exogenous glucose influx, endogenous glucose production, as well as the glucose uptake into peripheral tissues (Priebe et al., 2010). Therefore, the differences in $\mathrm{iAUC}_{0-6 \mathrm{~h}}$ for glucose may be due to a limited ability of the liver to convert fructose (and glycerol) into glucose. To assess appearance of exogenous substrates into the systemic circulation and to obtain indications on hepatic conversion into glucose, each calf (except for the CON group) received $1.5 \mathrm{~g}$ of the corresponding $\mathrm{U}_{-}{ }^{13} \mathrm{C}$ substrate. The $\Delta\left[{ }^{13} \mathrm{C}\right]$-glucose levels increased in all groups (Fig-

Table 2. Insulin sensitivity, fasting plasma metabolite and hormone concentrations, and the urinary excretion of glucose and stress-related markers (means $\pm \mathrm{SEM}$ ) in veal calves fed a control milk replacer (CON; $462 \mathrm{~g}$ of lactose $/ \mathrm{kg}$ of milk replacer; $\mathrm{n}=10)$ or a milk replacer in which $150 \mathrm{~g}$ of lactose/kg of milk replacer was replaced by isoenergetic amounts of glucose $(\mathrm{GLU} ; \mathrm{n}=9)$, fructose (FRU; $\mathrm{n}=10)$, or glycerol $(\mathrm{GLY} ; \mathrm{n}=10)$ for a period of $55 \mathrm{~d}$ (measurement period 2)

\begin{tabular}{|c|c|c|c|c|c|}
\hline \multirow[b]{2}{*}{ Item $^{1}$} & \multicolumn{4}{|c|}{ Treatment } & \multirow[b]{2}{*}{$P$-value } \\
\hline & $\mathrm{CON}$ & GLU & FRU & GLY & \\
\hline \multicolumn{6}{|l|}{ Insulin sensitivity } \\
\hline $\mathrm{IS}_{\text {minmod }} \times 10^{-4},\left[(\mathrm{mU} / \mathrm{L})^{-1} \times \min ^{-1}\right]$ & $1.04 \pm 0.21$ & $1.23 \pm 0.23$ & $0.83 \pm 0.14$ & $0.75 \pm 0.11$ & 0.702 \\
\hline QUICKI $\times 10^{1}$ & $3.30 \pm 0.09$ & $3.39 \pm 0.1$ & $3.39 \pm 0.07$ & $3.43 \pm 0.08$ & 0.203 \\
\hline \multicolumn{6}{|l|}{ Fasting plasma concentration } \\
\hline Glucose $(\mathrm{mmol} / \mathrm{L})$ & $5.7 \pm 0.1^{\mathrm{ab}}$ & $5.3 \pm 0.1^{\mathrm{a}}$ & $5.8 \pm 0.1^{\mathrm{b}}$ & $5.6 \pm 0.1^{\mathrm{ab}}$ & 0.016 \\
\hline Insulin $(\mathrm{mU} / \mathrm{L})$ & $12.7 \pm 2.2$ & $10.8 \pm 1.3$ & $9.8 \pm 1.8$ & $11.7 \pm 2.1$ & 0.786 \\
\hline Triglycerides (mmol/L) & $0.15 \pm 0.01$ & $0.15 \pm 0.01$ & $0.13 \pm 0.01$ & $0.14 \pm 0.01$ & 0.939 \\
\hline High-density lipoprotein-cholesterol (mmol/L) & $2.3 \pm 0.2$ & $2.6 \pm 0.2$ & $3.1 \pm 0.2$ & $2.7 \pm 0.1$ & 0.078 \\
\hline Low-density lipoprotein-cholesterol (mmol/L) & $0.41 \pm 0.06$ & $0.54 \pm 0.07$ & $0.68 \pm 0.10$ & $0.56 \pm 0.07$ & 0.135 \\
\hline \multicolumn{6}{|l|}{ Urinary excretion } \\
\hline Glucose $(\mathrm{g} / \mathrm{d})$ & $26.9 \pm 3.9^{\mathrm{a}}$ & $43.0 \pm 10.6^{\mathrm{a}}$ & $3.6 \pm 1.0^{\mathrm{b}}$ & $6.3 \pm 1.7^{\mathrm{b}}$ & $<0.001$ \\
\hline Adrenaline $(\mu \mathrm{g} / \mathrm{kg}$ of BW per day) & $0.07 \pm 0.01$ & $0.05 \pm 0.01$ & $0.06 \pm 0.01$ & $0.05 \pm 0.01$ & 0.251 \\
\hline Noradrenaline $(\mu \mathrm{g} / \mathrm{kg}$ of BW per day) & $0.68 \pm 0.08$ & $0.68 \pm 0.10$ & $0.77 \pm 0.07$ & $0.65 \pm 0.10$ & 0.239 \\
\hline Dopamine $(\mu \mathrm{g} / \mathrm{kg}$ of BW per day) & $0.71 \pm 0.11$ & $0.77 \pm 0.09$ & $0.83 \pm 0.05$ & $0.68 \pm 0.10$ & 0.143 \\
\hline Cortisol ( $\mu \mathrm{g} / \mathrm{kg}$ of BW per day) & $0.07 \pm 0.01$ & $0.08 \pm 0.02$ & $0.08 \pm 0.01$ & $0.06 \pm 0.01$ & 0.499 \\
\hline
\end{tabular}

\footnotetext{
${ }^{\mathrm{a}, \mathrm{b}}$ Different superscripts indicate pairwise differences $(P<0.05)$.

${ }^{1} \mathrm{IS}_{\text {minmod }}=$ insulin sensitivity derived from MinMod Millenium (MinMod Inc., Los Angeles, CA); QUICKI = quantitative insulin sensitivity
} index. 
ure 2) and, as expected, the $\mathrm{iAUC}_{0-6 \mathrm{~h}}$ differed between treatments, with GLU calves being substantially higher than FRU and GLY calves, and GLY being higher than FRU. This indicates that fructose and glycerol are (partly) converted to glucose in calves and may partly explain the differences observed in postprandial glucose concentrations. Nevertheless, the rates of conversion could not be calculated in our experiment, as the whole body glucose flux was not determined. In humans, between 29 and $50 \%$ of ingested fructose is converted to glucose within first $6 \mathrm{~h}$ (Delarue et al., 1993; Tran et al., 2010). In our experiment, the plasma ${ }^{13} \mathrm{C}$-glucose enrichment increased consistently within the first $6 \mathrm{~h}$. This indicates that, for calves, an incomplete conversion of fructose to glucose occurs within the first $6 \mathrm{~h}$ after intake. Gluconeogenesis from glycerol has also been studied in humans, although less extensive than fructose; Massicotte et al. (2006) found that approximately $9 \%$ is converted to glucose within the first $2 \mathrm{~h}$ after ingestion. Glycerol is also a known glucogenic precursor in ruminants (i.e., cows and sheep), although conversion rates have not been quantified (Aschenbach et al., 2010; Werner Omazic et al., 2015).

Urinary glucose excretion was significantly higher in CON and GLU calves than in FRU and GLY calves, where the urinary excretion was negligible. Excretion of glucose via urine is a result of hyperglycemia (Chao, 2014; Wilding, 2014); this occurs when the renal threshold for glucose reabsorption is exceeded. In our experiment, the plasma glucose peak levels for the CON and GLU calves exceeded the renal threshold of 8.3 to 11.1 mmol/L in calves (Wijayasinghe et al., 1984; Scholz and
Hoppe, 1987; Hostettler-Allen et al., 1994; Stanley et al., 2002), and therefore urinary excretion was expected in these groups. Glucosuria is frequently observed in milk-fed calves (Hostettler-Allen et al., 1994; Hugi et al., 1997; Kaufhold et al., 2000). Although urinary glucose excretion differed between treatments, IS did not differ. This indicates that urinary glucose excretion in calves is not associated with insulin resistance, but rather relates to exceeding the glucose renal threshold.

Based on the negative effect of GLU calves on postprandial glucose homeostasis (i.e., significantly greater blood glucose levels), and glycosuria for GLU and CON, compared with FRU and GLY calves, it could be expected that calves assigned to the first 2 treatments would be more insulin resistant. Chronic postprandial hyperglycemia can lead to glucotoxicity, which can ultimately result in insulin resistance and diabetes (Campos, 2012); however, this was not confirmed by the IS measurements.

\section{Development of IS}

The absence of effects on IS may be explained by the already low IS in calves before the dietary intervention. The average IS before the intervention was $1.2 \pm 0.1$ $\times 10^{-4}\left[(\mathrm{mU} / \mathrm{L})^{-1} \times \mathrm{min}^{-1}\right]$, which is $\sim 10 \times$ lower than in neonatal calves at 3 and 6 wk of age (Stanley et al., 2002) and $\sim 3$ to $6 \times$ lower than in nonruminants (Caumo et al., 2000; Stefanovski et al., 2011). Instead, values were more comparable to those in lactating cows (Stanley et al., 2002). Whether the lactose replacers

Table 3. Postprandial responses of plasma glucose and insulin, and ${ }^{13} \mathrm{C}$-enrichment in plasma glucose (means \pm SEM) in veal calves fed a control milk replacer $(\mathrm{CON} ; 462 \mathrm{~g}$ of lactose $/ \mathrm{kg}$ of milk replacer; $\mathrm{n}=10)$ or a milk replacer in which $150 \mathrm{~g}$ of lactose $/ \mathrm{kg}$ of milk replacer was replaced by isoenergetic amounts of glucose (GLU; $\mathrm{n}=9)$, fructose (FRU; $\mathrm{n}=10)$, or glycerol (GLY; $\mathrm{n}=10)$ for a period of $51 \mathrm{~d}$

\begin{tabular}{|c|c|c|c|c|c|}
\hline Item $^{1}$ & \multicolumn{4}{|c|}{ Treatment } & $P$-value \\
\hline \multicolumn{6}{|l|}{ Plasma glucose concentration } \\
\hline$\Delta \mathrm{C}_{\max }(\mathrm{mmol} / \mathrm{L})$ & $4.7 \pm 0.5^{\mathrm{ab}}$ & $6.3 \pm 0.4^{\mathrm{a}}$ & $3.5 \pm 0.3^{\mathrm{b}}$ & $3.7 \pm 0.4^{\mathrm{b}}$ & $<0.001$ \\
\hline Time to maximum (min) & $56 \pm 9$ & $77 \pm 20$ & $50 \pm 17$ & $54 \pm 4$ & 0.534 \\
\hline $\mathrm{iAUC}_{0-6 \mathrm{~h}}$ & $761 \pm 84^{\mathrm{b}}$ & $1,233 \pm 110^{\mathrm{a}}$ & $383 \pm 77^{\mathrm{c}}$ & $560 \pm 91^{\mathrm{bc}}$ & $<0.001$ \\
\hline$\Delta \mathrm{C}_{\max }(\mathrm{mU} / \mathrm{L})$ & $909 \pm 133^{\mathrm{a}}$ & $831 \pm 79^{\mathrm{a}}$ & $478 \pm 85^{\mathrm{b}}$ & $569 \pm 68^{\mathrm{ab}}$ & 0.008 \\
\hline Time to maximum (min) & $150 \pm 10$ & $140 \pm 10$ & $130 \pm 16$ & $126 \pm 7$ & 0.435 \\
\hline $\mathrm{iAUC}_{0-6 \mathrm{~h}} \times 10^{3}$ & $146 \pm 21^{\mathrm{a}}$ & $156 \pm 11^{\mathrm{a}}$ & $72 \pm 11^{\mathrm{b}}$ & $90 \pm 9^{b}$ & $<0.001$ \\
\hline \multirow{2}{*}{\multicolumn{6}{|c|}{${ }^{13} \mathrm{C}$ enriched plasma glucose ${ }^{2}$}} \\
\hline & $4.8 \pm 1.0^{3}$ & $887 \pm 55^{\mathrm{a}}$ & $151 \pm 14^{\mathrm{b}}$ & $250 \pm 18^{\mathrm{c}}$ & $<0.001$ \\
\hline
\end{tabular}


would have an effect on younger calves (which could be more sensitive to insulin) requires further study.

Several factors may contribute to the (decreased) IS observed in veal calves. One factor that may contribute is the high fat content in conventional calf MR $(\sim 200$ $\mathrm{g} / \mathrm{kg}$ of MR). The composition of the digestible energy intake in veal calves MR (i.e., high fat and carbohydrate content) is similar to that of the adult western human diet (Schwarz et al., 2003; Cordain et al., 2005). In humans, high dietary fat intake was found to be associated with insulin resistance (Storlien et al., 1996; Vessby, 2000; Marshall and Bessesen, 2002). However,
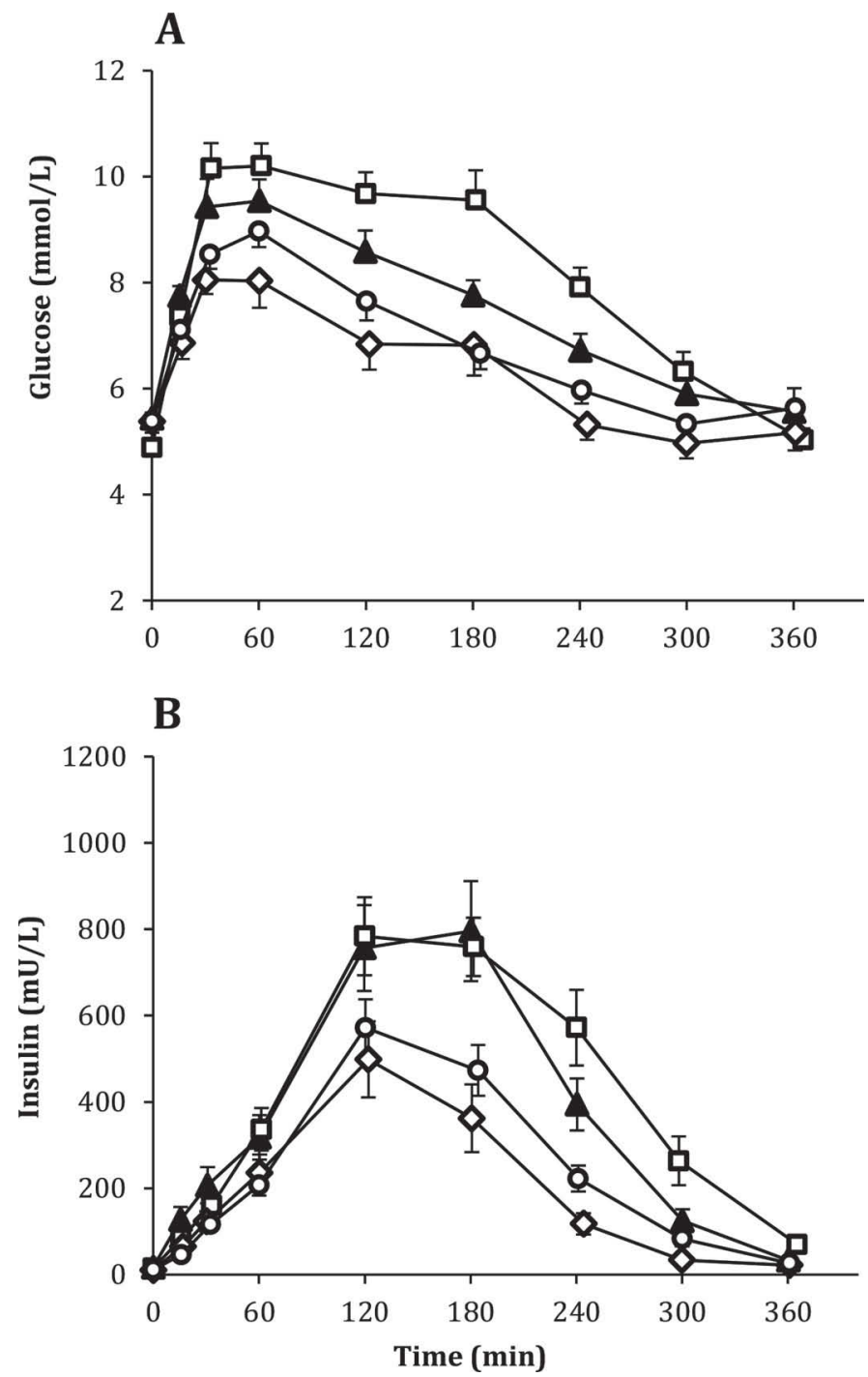

Figure 1. Plasma glucose (A) and insulin (B) responses in veal calves fed (at time $=0$ ) a control milk replacer $(\boldsymbol{\Lambda}, 462 \mathrm{~g}$ of lactose $/ \mathrm{kg}$ of milk replacer; $\mathrm{n}=10$ ) or a milk replacer in which $150 \mathrm{~g}$ of lactose/ $\mathrm{kg}$ of milk replacer was replaced by isoenergetic amounts of glucose ( $\square$; $\mathrm{n}=9$ ), fructose $(\diamond ; \mathrm{n}=10)$, or glycerol $(\bigcirc ; \mathrm{n}=10)$ for a period of 51 d. Error bars represent SEM. Calculated parameters and statistics are given in Table 3 . despite their higher glucose (but lower fat) intake, pigs and rats generally do not suffer from insulin resistance as much as veal calves. It may be speculated that, apart from the species difference, interactions between dietary fat and glucose may contribute to reduced IS in veal calves. Another factor that may contribute to the (decreased) IS observed in veal calves is the discrepancy between their diet and ontogenetic background. Insulin resistance seems to be age-dependent in veal calves (Hugi et al., 1997, 1998). In nature, calves between 4 and 6 mo of age are grazing and plant fragments are fermented in the rumen along with the production of VFA such as acetate, propionate, and butyrate as the main sources of energy. Therefore, the veal calf, which is an ontogenetic ruminant, may not be equipped with the genetic capacity to deal with the large amounts of lactose (e.g., the capacity to use the glucose as precursor for de novo fatty acid synthesis; Roehrig et al., 1988). This may explain why high lactose intake might induce insulin resistance in veal calves and why calves on conventional MR do not synthesize body fat from dietary carbohydrates (van den Borne et al., 2007). Nevertheless, whether the decrease in IS is diet-related or part of the genetic programming of calves (transition from preruminant to ruminant) is not clear and needs to be investigated. Another factor that can modulate IS is environmental stress (Sato et al., 2011). Hugi et al. (1997) measured the urinary excretion of noradrenaline and dopamine in veal calves and found a significant

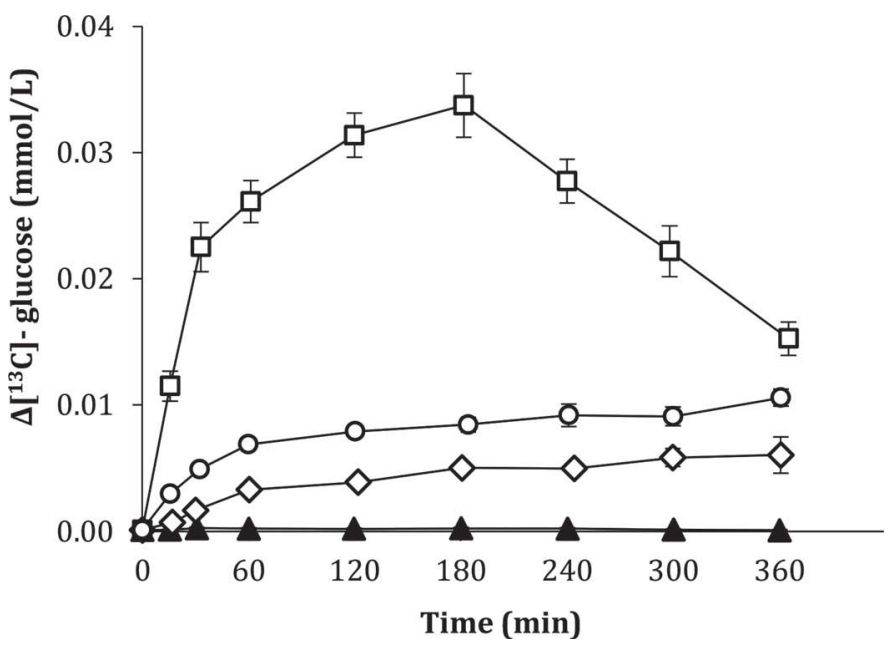

Figure 2. Changes in plasma $\Delta^{13} \mathrm{C}$-glucose concentration in veal calves fed (at time $=0$ ) a control milk replacer $(\boldsymbol{\Lambda}, 462 \mathrm{~g}$ of lactose $/ \mathrm{kg}$ of milk replacer; $\mathrm{n}=10$ ) or a milk replacer in which $150 \mathrm{~g}$ of lactose/ $\mathrm{kg}$ of milk replacer was replaced by isoenergetic amounts of glucose ( $\square$; $\mathrm{n}=9)$, fructose $(\diamond ; \mathrm{n}=6)$, or glycerol $(O ; \mathrm{n}=10)$ for a period of 51 d. On top of the milk replacer diets (except for the control group) 1.5 $\mathrm{g}$ of the corresponding $\mathrm{U}_{-}{ }^{13} \mathrm{C}$ substrate (i.e., ${ }^{13} \mathrm{C}$-glucose, fructose, or glycerol) was added to their diets on d 46. Error bars represent SEM. Calculated parameters and statistics are given in Table 3. 
increase with age. They concluded that the enhanced activity of the nervous system (stress) might have contributed to the decrease in IS. In our study, however, none of the stress-related markers increased with age and no treatment effect was noted. In addition, we performed Pearson bivariate correlation analysis between the measured IS values and the rates of urinary excretion of the different stress markers (data not shown). Significant correlations were not found between IS and any of the stress markers, suggesting that stress did not significantly affect IS in the current study.

\section{Fasting Blood Glucose, Insulin, Triglycerides, and Cholesterol}

In our study, an increase in fasting plasma insulin levels was observed for all treatments, which (at constant fasting glucose levels) suggests a decrease in hepatic IS (Muniyappa et al., 2008). The increase in plasma insulin is in agreement with findings by Breier et al. (1988) and Hugi et al. (1997), but in contrast with Hostettler-Allen et al. (1994), who did not detect an age-related increase in fasting plasma insulin levels.

In humans, insulin resistance is also often associated with dyslipidemia, characterized by a high ratio between triglycerides and HDL cholesterol (Li et al., 2008; Bitzur et al., 2009); however, whether this is also true for calves is unknown. Nevertheless, in our trial the triglyceride-to-HDL cholesterol ratios were extremely low (ratios <1) and decreased with age in all groups (lower triglyceride concentrations), suggesting no evidence of dyslipidemia in these calves.

\section{CONCLUSIONS}

Replacing $150 \mathrm{~g}$ of lactose $/ \mathrm{kg}$ of MR with glucose, fructose, or glycerol does affect postprandial glucose homeostasis. Replacement with glucose leads to increased postprandial blood glucose levels, but similar blood insulin levels and urinary glucose losses. Fructose and glycerol are (partly) converted into glucose and lead to reduced postprandial glucose and insulin levels when lactose is replaced with fructose, and reduced insulin levels when replaced with glycerol. Both substrates do not lead to significant urinary glucose losses. Despite differences in postprandial glucose homeostasis, lactose replacement did not affect IS.

\section{ACKNOWLEDGMENTS}

The authors thank Gerlof Reckman, Theo Boer, and Jeltje Kloosterman for their laboratory assistance (University Medical Centre Groningen), and the animal caretakers at Carus, the experimental facilities of Wa- geningen University. This project was jointly financed by the European Union, European Regional Development Fund and the Ministry of Economic Affairs, Agriculture and Innovation, Peaks in the Delta, the Municipality of Groningen, the Provinces of Groningen, Fryslân and Drenthe as well as the Dutch Carbohydrate Competence Center (CCC2 WP21). Financial support was also provided by Tereos Syral (Marckolsheim, France), VanDrie Group (Mjidrecht, the Netherlands), and Wageningen University (Wageningen, the Netherlands).

\section{REFERENCES}

Aschenbach, J. R., N. B. Kristensen, S. S. Donkin, H. M. Hammon, and G. B. Penner. 2010. Gluconeogenesis in dairy cows: The secret of making sweet milk from sour dough. IUBMB Life 62:869-877.

Bergman, R. N., Y. Z. Ider, C. R. Bowden, and C. Cobelli. 1979. Quantitative estimation of insulin sensitivity. Am. J. Physiol. 236:E667-E677.

Bitzur, R., H. Cohen, Y. Kamari, A. Shaish, and D. Harats. 2009. Triglycerides and HDL cholesterol stars or second leads in diabetes? Diabetes Care 32(Suppl 2):S373-377.

Boston, R. C., D. Stefanovski, P. J. Moate, A. E. Sumner, R. M. Watanabe, and R. N. Bergman. 2003. MINMOD Millennium: A computer program to calculate glucose effectiveness and insulin sensitivity from the frequently sampled intravenous glucose tolerance test. Diabetes Technol. Ther. 5:1003-1015.

Breier, B. H., P. D. Gluckman, and J. J. Bass. 1988. Plasma concentrations of insulin-like growth factor-I and insulin in the infant calf: Ontogeny and influence of altered nutrition. J. Endocrinol. 119:43-50.

Burt, A. W. A., and S. M. Irvine. 1970. Carbohydrates in milk replacers for calves. J. Sci. Food Agric. 21:342-346.

Campos, C. 2012. Chronic hyperglycemia and glucose toxicity: Pathology and clinical sequelae. Postgrad. Med. 124:90-97.

Caumo, A., R. N. Bergman, and C. Cobelli. 2000. Insulin sensitivity from meal tolerance tests in normal subjects: A minimal model index. J. Clin. Endocrinol. Metab. 85:4396-4402.

Chao, E. C. 2014. SGLT-2 Inhibitors: A new mechanism for glycemic control. Clin. Diabetes 32:4-11.

Chen, H., G. Sullivan, L. Q. Yue, A. Katz, and M. J. Quon. 2003. QUICKI is a useful index of insulin sensitivity in subjects with hypertension. Am. J. Physiol. Endocrinol. Metab. 284:E804-E812.

Coombe, N. B., and R. H. Smith. 1974. Digestion and absorption of starch, maltose and lactose by the preruminant calf. Br. J. Nutr. $31: 227-235$.

Cordain, L., S. B. Eaton, A. Sebastian, N. Mann, S. Lindeberg, B. A. Watkins, J. H. O'Keefe, and J. Brand-Miller. 2005. Origins and evolution of the Western diet: Health implications for the 21st century. Am. J. Clin. Nutr. 81:341-354.

de Jong, W. H., E. G. de Vries, B. H. Wolffenbuttel, and I. P. Kema. 2010. Automated mass spectrometric analysis of urinary free catecholamines using on-line solid phase extraction. J. Chromatogr. B Analyt. Technol. Biomed. Life Sci. 878:1506-1512.

Delarue, J., S. Normand, C. Pachiaudi, M. Beylot, F. Lamisse, and J. P. Riou. 1993. The contribution of naturally labelled $13 \mathrm{C}$ fructose to glucose appearance in humans. Diabetologia 36:338-345.

Eelderink, C., T. C. W. Moerdijk-Poortvliet, H. Wang, M. Schepers, T. Preston, T. Boer, R. J. Vonk, H. Schierbeek, and M. G. Priebe. 2012. The glycemic response does not reflect the in vivo starch digestibility of fiber-rich wheat products in healthy men. J. Nutr. 142:258-263.

Foster-Powell, K., S. H. A. Holt, and J. C. Brand-Miller. 2002. International table of glycemic index and glycemic load values: 2002 . Am. J. Clin. Nutr. 76:5-56.

Gerrits, W. J. J., J. J. G. C. van den Borne, and J. W. Blum. 2008. Low-dietary protein intake induces problems with glucose homeo- 
stasis and results in hepatic steatosis in heavy milk-fed calves. Domest. Anim. Endocrinol. 35:121-129.

Gilbert, M. S., A. J. Pantophlet, H. Berends, A. M. Pluschke, J. J. G. C. van den Borne, W. H. Hendriks, H. A. Schols, and W. J. J. Gerrits. 2015a. Fermentation in the small intestine contributes substantially to intestinal starch disappearance in calves. J. Nutr. 145:1147-1155.

Gilbert, M. S., A. J. Pantophlet, J. J. G. C. van den Borne, W. H. Hendriks, H. A. Schols, and W. J. J. Gerrits. 2016. Replacing lactose with glucose, fructose or glycerol does not affect energy retention in veal calves. J. Dairy Sci. 99:1121-1133.

Gilbert, M. S., J. J. G. C. van den Borne, H. Berends, A. J. Pantophlet, H. A. Schols, and W. J. J. Gerrits. 2015b. A titration approach to identify the capacity for starch digestion in milk-fed calves. Animal 9:249-257.

Grunnet, N., and F. Lundquist. 1967. Kinetics of glycerol kinases from mammalian liver and Candida mycoderma. Eur. J. Biochem. 3:78-84.

Hostettler-Allen, R. L., L. Tappy, and J. W. Blum. 1994. Insulin resistance, hyperglycemia, and glucosuria in intensively milk-fed calves. J. Anim. Sci. 72:160-173.

Hotamisligil, G. S. 2006. Inflammation and metabolic disorders. Nature 444:860-867.

Howlett, J., and M. Ashwell. 2008. Glycemic response and health: Summary of a workshop. Am. J. Clin. Nutr. 87:212S-216S.

Hugi, D., R. M. Bruckmaier, and J. W. Blum. 1997. Insulin resistance, hyperglycemia, glucosuria, and galactosuria in intensively milk-fed calves: Dependency on age and effects of high lactose intake. J. Anim. Sci. 75:469-482.

Hugi, D., L. Tappy, H. Sauerwein, R. M. Bruckmaier, and J. W. Blum. 1998. Insulin-dependent glucose utilization in intensively milk-fed veal calves is modulated by supplemental lactose in an age-dependent manner. J. Nutr. 128:1023-1030.

Jones, R. L., L. J. Owen, J. E. Adaway, and B. G. Keevil. 2012. Simultaneous analysis of cortisol and cortisone in saliva using XLC-MS/ MS for fully automated online solid phase extraction. J. Chromatogr. B Analyt. Technol. Biomed. Life Sci. 881-882:42-48.

Kaufhold, J., H. M. Hammon, and J. W. Blum. 2000. Fructo-oligosaccharide supplementation: Effects on metabolic, endocrine and hematological traits in veal calves. J. Vet. Med. A Physiol. Pathol. Clin. Med. 47:17-29.

Le Floch, J. P., P. Escuyer, E. Baudin, D. Baudon, and L. Perlemuter 1990. Blood glucose area under the curve. Methodological aspects. Diabetes Care 13:172-175.

Li, C., E. S. Ford, Y. X. Meng, A. H. Mokdad, and G. M. Reaven. 2008. Does the association of the triglyceride to high-density lipoprotein cholesterol ratio with fasting serum insulin differ by race/ ethnicity? Cardiovasc. Diabetol. 7:4.

Marshall, J. A., and D. H. Bessesen. 2002. Dietary fat and the development of type 2 diabetes. Diabetes Care 25:620-622.

Massicotte, D., A. Scotto, F. Péronnet, H. M'Kaouar, M. Milot, and C. Lavoie. 2006. Metabolic fate of a large amount of 13C-glycerol ingested during prolonged exercise. Eur. J. Appl. Physiol. 96:322329

Muniyappa, R., S. Lee, H. Chen, and M. J. Quon. 2008. Current approaches for assessing insulin sensitivity and resistance in vivo: Advantages, limitations, and appropriate usage. Am. J. Physiol. Endocrinol. Metab. 294:E15-E26.

Pacini, G., and R. N. Bergman. 1986. MINMOD: A computer program to calculate insulin sensitivity and pancreatic responsivity from the frequently sampled intravenous glucose tolerance test. Comput. Methods Programs Biomed. 23:113-122.

Priebe, M. G., H. Wang, D. Weening, M. Schepers, T. Preston, and R. J. Vonk. 2010. Factors related to colonic fermentation of nondigestible carbohydrates of a previous evening meal increase tissue glucose uptake and moderate glucose-associated inflammation. Am. J. Clin. Nutr. 91:90-97.
Roehrig, K., K. E. Nestor, and D. L. Palmquist. 1988. ATP citrate lyase activity in liver and adipose tissue of veal or ruminating calves (Bos taurus). Comp. Biochem. Physiol. B 90:147-149.

Sato, M., S. Ishibashi, M. Higashimoto, Y. Kadota, T. Kawakami, and S. Suzuki. 2011. Early changes induced by environmental stresses in insulin sensitivity-related genes. Eur. J. Pharmacol. 668:472476.

Schaefer, E. J., J. A. Gleason, and M. L. Dansinger. 2009. Dietary fructose and glucose differentially affect lipid and glucose homeostasis. J. Nutr. 139:1257S-1262S.

Scholz, H., and S. Hoppe. 1987. Renal glucose loss after intravenous glucose-infusion in calves. Dtsch. Tierarztl. Wochenschr. 94:473476.

Schwarz, J. M., P. Linfoot, D. Dare, and K. Aghajanian. 2003. Hepatic de novo lipogenesis in normoinsulinemic and hyperinsulinemic subjects consuming high-fat, low-carbohydrate and low-fat, high-carbohydrate isoenergetic diets. Am. J. Clin. Nutr. 77:43-50.

Shoelson, S. E., S. Lee, and A. B. Goldfire. 2006. Inflammation and insulin resistance. J. Clin. Invest. 116:1793-1801.

Sidák, Z. 1967. Rectangular confidence regions for the means of multivariate normal distributions. J. Am. Stat. Assoc. 62:626-633.

Stanley, C. C., C. C. Williams, B. F. Jenny, J. M. Fernandez, H. G. Bateman, W. A. Nipper, J. C. Lovejoy, D. T. Gantt, and G. E. Goodier. 2002. Effects of feeding milk replacer once versus twice daily on glucose metabolism in holstein and jersey calves. J. Dairy Sci. 85:2335-2343.

Stefanovski, D., J. M. Richey, O. Woolcott, M. Lottati, D. Zheng, L. N. Harrison, V. Ionut, S. P. Kim, I. Hsu, and R. N. Bergman. 2011 Consistency of the disposition index in the face of diet induced insulin resistance: Potential role of FFA. PLoS ONE 6:e18134.

Storlien, L. H., L. A. Baur, A. D. Kriketos, D. A. Pan, G. J. Cooney, A. B. Jenkins, G. D. Calvert, and L. V. Campbell. 1996. Dietary fats and insulin action. Diabetologia 39:621-631.

Sun, S. Z., and M. W. Empie. 2012. Fructose metabolism in humansWhat isotopic tracer studies tell us. Nutr. Metab. (Lond) 9:89

Tran, C., D. Jacot-Descombes, V. Lecoultre, B. A. Fielding, G. Carrel, K. A. Lê, P. Schneiter, M. Bortolotti, K. N. Frayn, and L. Tappy. 2010. Sex differences in lipid and glucose kinetics after ingestion of an acute oral fructose load. Br. J. Nutr. 104:1139-1147.

van den Borne, J. J. G. C., G. E. Lobley, M. W. A. Verstegen, J. M. Muijlaert, S. J. J. Alferink, and W. J. J. Gerrits. 2007. Body fat deposition does not originate from carbohydrates in milk-fed calves. J. Nutr. 137:2234-2241.

Van Es, A. J. H., H. J. Nijkamp, E. J. Van Weerden, and K. K. Van Hellemond. 1967. Energy, carbon and nitrogen balance experiments with veal calves. Pages 197-201 in Energy Metabolism of Farm Animals. K. L. Blaxter, J. Kielanowski, and G. Thorbek, ed. Oriel Press, Newcastle-upon-Tyne, UK.

Vessby, B. 2000. Dietary fat and insulin action in humans. Br. J. Nutr 83:S91-S96.

Vonk, R. J., R. E. Hagedoorn, R. De Graaff, H. Elzinga, S. Tabak, Y. X. Yang, and F. Stellaard. 2000a. Digestion of so-called resistant starch sources in the human small intestine. Am. J. Clin. Nutr. 72:432-438.

Vonk, R. J., Y. Lin, H. A. Koetse, C. Huang, G. Zeng, H. Elzinga, J. Antoine, and F. Stellaard. 2000b. Lactose (mal)digestion evaluated by the 13C-lactose digestion test. Eur. J. Clin. Invest. 30:140-146.

Werner Omazic, A., C. Kronqvist, L. Zhongyan, H. Martens, and K. Holtenius. 2015. The fate of glycerol entering the rumen of dairy cows and sheep. J. Anim. Physiol. Anim. Nutr. (Berl.) 99:258-264.

Wijayasinghe, M. S., N. E. Smith, and R. L. Baldwin. 1984. Growth, health, and blood glucose concentrations of calves fed high-glucose or high-fat milk replacers. J. Dairy Sci. 67:2949-2956.

Wilding, J. P. H. 2014. The role of the kidneys in glucose homeostasis in type 2 diabetes: Clinical implications and therapeutic significance through sodium glucose co-transporter 2 inhibitors. Metabolism 63:1228-1237. 